\title{
Mild Anemia
}

National Cancer Institute

\section{Source}

National Cancer Institute. Mild Anemia. NCI Thesaurus. Code C82909.

Anemia not associated with symptoms of fatigue, headaches, palpitations, or shortness

of breath. In asymptomatic anemia the hematocrit levels usually range from 32 to 35\%. 